\title{
The Evolutionary Importance of Cues in Protective Mimicry
}

\author{
Thomas de Solan ${ }^{1}$ and Thomas G. Aubier ${ }^{2 *}$ \\ ${ }^{1}$ Centre d'Ecologie Fonctionnelle et Evolutive, CNRS, Université de Montpellier, Université Paul Valéry Montpellier 3, EPHE, \\ IRD, Montpellier, France, ${ }^{2}$ Department of Evolutionary Biology and Environmental Studies, University of Zurich, Zurich, \\ Switzerland
}

Keywords: aposematism, Batesian mimicry, Müllerian mimicry, signal, imperfect mimicry, diversity

OPEN ACCESS

Edited by:

Piotr Jablonski,

Seoul National University, South Korea

Reviewed by:

Simcha Lev-Yadun,

University of Haifa, Israel

David Pfennig,

University of North Carolina at Chapel

Hill, United States

${ }^{*}$ Correspondence:

Thomas G. Aubie

thomas.aubier@normalesup.org

Specialty section:

This article was submitted to

Behavioral and Evolutionary Ecology,

a section of the journal

Frontiers in Ecology and Evolution

Received: 02 May 2019

Accepted: 12 July 2019

Published: 06 August 2019

Citation:

de Solan T and Aubier TG (2019) The

Evolutionary Importance of Cues in

Protective Mimicry.

Front. Ecol. Evol. 7:283.

doi: 10.3389/fevo.2019.00283
Predators often avoid toxic, unpalatable, or otherwise unprofitable prey because of innate biases or past unpleasant experiences. In both cases, the association between prey appearance and unprofitability has favored an anti-predator strategy called "aposematism" (Poulton, 1890). In short, aposematic prey benefit from reduced predation because predators perceive the prey phenotype as a warning (Wallace, 1882). Aposematic traits take the form of spectacular conspicuous colorations in many taxa, in particular in snakes (Smith, 1977), amphibians (Rudh and Qvarnström, 2013), insects (Wilson et al., 2015; Motyka et al., 2018) and spiny plants (Lev-Yadun, 2016). As such, they have enthralled many evolutionary biologists and ecologists, whose research greatly improved our understanding of local adaptation (Mallet and Barton, 1989), speciation (Merrill et al., 2012), community dynamics (Chazot et al., 2014), and predator foraging decisions (Skelhorn et al., 2016). In the literature, aposematism is therefore often equated with colorations that are consistently conspicuous (but see recent studies on "switchable" aposematic signals; e.g., Kang et al., 2016a,b). We argue here that this focus on conspicuous colorations has led to researchers overlooking other components of prey phenotype. Aposematism relies not only on "signaling traits" (like conspicuous coloration), which evolve through natural selection imposed by predators, but also on "cues" (e.g., body shape, behavior, or non-conspicuous coloration), the evolution of which is determined mainly by environment, sexual selection or developmental constraints (Maynard-Smith and Harper, 2003; Scott-Phillips, 2008). In this opinion piece, we aim at highlighting the underappreciated role of cues in the evolution of warning signals in the context of protective mimicry.

\section{DEFINING SIGNALS AND CUES IN AN EVOLUTIONARY CONTEXT}

Communication and signaling in animals have long been recognized to rely on the detection of both signals and cues (Scott-Phillips, 2008; Bro-Jørgensen, 2010; Higham and Hebets, 2013). Yet, the terms "signal" and "cue" have been fraught with semantic disagreement (Maynard-Smith and Harper, 2003; Scott-Phillips, 2008). In communication theory, cues and signals have been defined from an informational point of view (Table 1). Cues are defined as incidental sources of information detected by "unintended" receivers, while signals are information addressed to "intended" receivers (Hasson, 1994; Greenfield, 2006). Yet, this distinction seems of little practical use in an evolutionary context. The terms "unintended" and "intended" do not make much sense in evolutionary biology and can be misleading (Font, 2018).

To better understand the implication of cues and signals for trait evolution, we need to consider definitions that are relevant in an evolutionary context (Table 1). Several authors adopted adaptationist definitions of cues and signals, generally in addition to the informational definitions (Maynard-Smith and Harper, 2003; Scott-Phillips, 2008; Bro-Jørgensen, 2010). If we focus on predator-prey interactions: in prey, signals are defined as traits that have evolved predominantly through differential predator avoidance as the result of predator decision making, while cues are 
TABLE 1 | Informational and adaptationist definitions of signal and cue in the case of protective mimicry.

\begin{tabular}{lll}
\hline Informational definition & $\begin{array}{l}\text { Adaptationist definition } \\
\text { (used in this manuscript) }\end{array}$ \\
\hline Signal & $\begin{array}{l}\text { Information addressed to } \\
\text { "intended" receivers through a } \\
\text { channel of communication }\end{array}$ & $\begin{array}{l}\text { Trait that has evolved predominantly } \\
\text { through differential predator } \\
\text { avoidance }\end{array}$ \\
Cue Incidental source of information & $\begin{array}{l}\text { Trait that has evolved predominantly } \\
\text { detected by "unintended" receivers }\end{array}$ & $\begin{array}{l}\text { (e.g., sexual selection, } \\
\text { developmental constraint) }\end{array}$ \\
&
\end{tabular}

traits that have evolved predominantly through other evolutionary forces. Of course, selection imposed by predators is likely to influence the evolution of all traits that are perceptible. The difference between cues and signals in a given species relies on the importance of selection that results from predator avoidance, compared to the other evolutionary forces acting on the trait. Therefore, a phenotypic trait that is a cue in one species can be a signal in another.

Numerous traits, including conspicuous coloration (Rojas et al., 2018), can serve several functions and the resulting phenotype frequently results from a trade-off among different evolutionary drivers. Consequently, distinguishing cues from signals in the field is challenging. The exact nature of selection acting on conspicuous signals has only recently been measured in the field (in butterflies; Chouteau et al., 2016). Therefore, the intensity of selection imposed by predators on non-conspicuous traits can be particularly difficult to assess (e.g., on flight behavior; Beccaloni, 1997).

Hereafter, we adopt the adaptationist definition of cues and signals to discuss the evolutionary importance of cues in protective mimicry. In examples, we classify phenotypic traits as signals or cues; but remember that those assertions require caution. In particular, what we call "cues" (and therefore "cue mimicry," see below) may not be considered as such under the informational point of view (e.g., Figures 1A,B).

\section{DISTINGUISHING CUE MIMICRY FROM SIGNAL MIMICRY}

Protective mimicry, when a species benefits from reduced predation by mimicking another unprofitable species, is one of the most celebrated examples of evolution by natural selection (Bates, 1862; Cott, 1940; Quicke, 2017). Species engaged in protective mimicry are traditionally defined as mimetic or model species, with the former being the species benefiting the most from mimicry (Cott, 1940; Ruxton et al., 2018). Communication between prey and predators determines the evolution of protective mimicry but, surprisingly, little attention has been given to the evolutionary implication of cues in protective mimicry. As signaling traits strongly stimulate the predator sensory system, most mimetic systems rely on "signal mimicry," whereby the mimetic signaling traits are similar to the model's signaling traits (Cott, 1940; Quicke, 2017). Nonetheless, predators also perceive cues, favoring the evolution of "cue mimicry," whereby the mimetic signaling traits are similar to some of the model's cues. In the case of cue mimicry, the same phenotypic trait is a signaling trait in the mimetic species, and a cue in the model species (Jamie, 2017).

In a recent review paper, Jamie (2017) proposed a conceptual framework considering the distinction between cues and signals to contrast and order all mimetic resemblances (protective mimicry, aggressive mimicry, rewarding mimicry). This framework highlights the evolutionary importance of cues in mimicry and distinguishes "cue mimicry" from "signal mimicry." Nonetheless, Jamie (2017) provided no convincing examples of cues involved in protective mimicry but instead discussed cases of masquerade where inanimate objects are mimicked. To fill this gap, we present below examples of "cue mimicry" in the context of protective mimicry. We then discuss the evolutionary consequences of this defensive strategy for the evolution of mimetic signals.

\section{CUE MIMICRY IN NATURE}

In nature, protective mimicry is often characterized by some forms of cue mimicry. One of its most striking examples is eyespots mimicry found in a wide variety of insects (Stevens, 2005). Eyespots usually take the form of a large dark central spot surrounded by a white border, and look like the eyes of large size vertebrates that are predators of the small birds attacking insects. The evolution of eyespots is determined by differential predation rate in insect mimetic species (De Bona et al., 2015), whereas the evolution of vertebrate eyes is determined by other selective pressures. As such, eyespots mimicry can be defined as cue mimicry. Another common example of cue mimicry is seen in the mimicry of ants. Ants are involved in many mimetic systems, especially with spiders as mimics, and yet rarely display conspicuous colorations (Huang et al., 2011). Most ant species can defend themselves (mandible, formic acid), making them unprofitable to most predators. Mimetic species with the same body shape, gait and colorations than the ants benefit from reduced predation (Figures 1A,B; McIver and Stonedahl, 1993; Nelson and Card, 2016). In the ant models, the evolution of these traits is mainly determined by environment and developmental constraints (except aposematic conspicuous coloration in some ant species), while it is determined by predator selective pressures in their mimics. Finally, cue mimicry is also found in plants. Several plant species produce a white trichome that is highly similar to a spider web, and thereby benefit from reduced herbivory (Yamazaki and Lev-Yadun, 2015). In spider model species, however, the web (here recognized as a component of the extended phenotype) has evolved through other evolutionary forces than predator avoidance. Another example of cue mimicry in plants is seen in species emitting the alarm pheromones of their aphid herbivore, thereby reducing herbivory by aphids (Gibson and Pickett, 1983). In aphids, releasing alarm pheromones does not reduce any death rate 


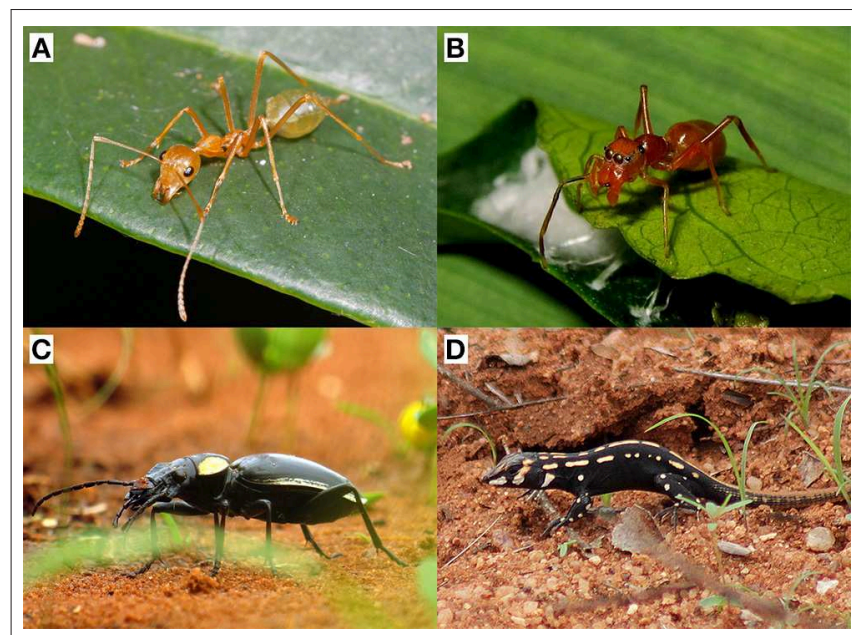

FIGURE 1 | Examples of cue mimicry in protective mimicry. The body shape of the ant Oecophylla smaragdina (A) is mimicked by the spider Myrmaplata plataleoides (B). Note that this instance of cue mimicry may not be considered as such under the informational approach (Table 1). In addition to signal mimicry, the gait of the beetle Anthia thoracica (C) is mimicked by the juvenile lizard Heliobolus lugubris (D). Photo credits: (A) Lek Khauv; (B) Jason Alexander; (C) Tjeerd de Wit; (D) Christine Sydes.

caused by other aphid individuals, making this adaptive ressemblance a case of cue mimicry. Cue mimicry also exists between plant species. Australian mistletoe species benefit from reduced herbivory by mimicking the foliage of their hosttree (Barlow and Wiens, 1977; Burns, 2010). Similarly, a vine, Boquila trifoliolata, has the same leave shape as its supporting plant (Gianoli and Carrasco-Urra, 2014). In both examples, the supporting species is considered as the model because they are little palatable. Here again, the foliage shape of models is probably determined by environment and developmental constraints, rather than herbivory. All these examples demonstrate that cue mimicry is not anecdotal and may be taxonomically widespread.

\section{CUE MIMICRY IN ASSOCIATION WITH SIGNAL MIMICRY}

Cue mimicry can be associated with signal mimicry in the same mimetic system. This is especially the case when model and mimic belong to different guilds and have very different ecology. For instance, in southern Africa, juveniles of the Heliobolus lugubris lizard species mimic a sympatric and noxious beetle species (Figures 1C,D; Huey and Pianka, 1977). The two species have a similar conspicuous coloration, a black coloration with white spots, but the lizard also has the same gait as the beetle, thereby increasing mimetic resemblance. Similar examples of signal mimicry paired with behavioral cue mimicry can be found in other mimetic systems involving vertebrate and invertebrate species (Vitt, 1992; Londoño et al., 2015). Likewise, some hoverfly species wave their darkened front legs, thereby mimicking the presence and movement of long antennae that are cues in conspicuously colored wasp models (Waldbauer, 1970).

Cue mimicry can also be associated with signal mimicry when model and mimic belong to the same guild. For instance, some aposematic species of Dilophotes beetles have different conspicuous mimetic signals (shared with different model species) depending on their sex (Motyka et al., 2018). In these species, males are smaller than females, and this sexual size dimorphism may have favored the evolution of sexual mimetic dimorphism. In model species, size is probably a cue, the evolution of which is primarily determined by developmental constraints. In the mimetic Dilophotes species, however, sexual size dimorphism strongly affects predator avoidance and has determined the evolution of different conspicuous mimetic signals in females and males. This example reveals how model's cues can potentially influence the signaling traits of the mimic, and thus demonstrates the importance of accounting for cues in theories on mimicry evolution.

\section{IMPLICATIONS OF CUE MIMICRY FOR MIMICRY EVOLUTION}

Accounting for cue mimicry may shed light on puzzling patterns observed in mimetic systems. Imperfect mimicry is found in many taxa (Vereecken and Schiestl, 2008; Penney et al., 2012), while a perfect resemblance should theoretically evolve by natural selection. Several hypotheses may explain this paradox (Kikuchi and Pfennig, 2013). Among those hypotheses, the backup signal hypothesis suggests that a weak resemblance between mimic and model can be compensated by additional backup signals, thereby maintaining imperfect mimicry on other signaling traits (Johnstone, 1996). Following this backup signal hypothesis, cue mimicry may evolve as a backup to imperfect signal mimicry. In particular, if mimetic and model species belong to different guilds and show strong phenotypic differences, perfect mimicry may be difficult to evolve and cue mimicry is likely to evolve as a backup to imperfect signal mimicry. Such situation is nicely illustrated with the example of the juvenile lizards mimicking the beetle's gait (Figures 1C,D) (Huey and Pianka, 1977), and may occur in many vertebrateinvertebrate mimetic systems (Vitt, 1992; Londoño et al., 2015). Overall, even in mimetic systems involving species from the same guild (e.g., Silva et al., 2016), cue mimicry can play an important role for the maintenance of imperfect mimicry.

Due to the differences of selective pressure acting on cues and signals, cues can maintain the diversity of mimetic signals among defended species (so-called "Müllerian mimicry"). Several distinct and stable Müllerian mimetic forms cooccurring in the same place have been observed, while a single shared mimetic form should provide increased protection against predators (Mallet and Joron, 1999). Several hypotheses may explain this phenomenon, like local adaptation (Mallet and Gilbert, 1995) or heterogeneity in micro-habitat use among species (Willmott et al., 2017), but to our knowledge, the implication of cues for the maintenance of Müllerian mimetic diversity has not been investigated. Predators use both signaling traits and cues to recognize their prey, so that mimicry based on signaling traits alone may not necessarily deceive predators. Contrary to signaling traits, selective pressure imposed by predation does not favor the evolution of shared cues in the 
model species. Differences in the cues of models could prevent the convergence of Müllerian mimetic forms and may explain the maintenance of diversity in some communities. Such a situation is illustrated by the case of Dilophotes beetles, the evolution of which is compelled by the size of their models (Motyka et al., 2018). This hypothesis remains to be investigated theoretically, and has received little empirical support so far, probably because of the oversight of cues in the literature on protective mimicry.

\section{CONCLUSION}

The literature on aposematism and mimicry has mainly focused on conspicuous signaling traits. While such focus has allowed for rapid advancement of the field, we may have minimized the implication of cues for the evolution of mimicry. As illustrated above, protective mimicry can occur without any form of conspicuous signal and, by focusing on conspicuous coloration, we may underestimate the predominance of protective mimicry in natural communities. A rigorous framework should be employed to detect such mimicry based on non-conspicuous traits (see de Jager and Anderson, 2019).

\section{REFERENCES}

Barlow, B. A., and Wiens, D. (1977). Host-parasite resemblance in Australian mistletoes: the case for cryptic mimicry. Evolution 31, 69-84. doi: 10.1111/j.1558-5646.1977.tb00983.x

Bates, H. W. (1862). Contributions to an insect fauna of the Amazon valley (Lepidoptera: Heliconidae). Trans. Linn. Soc. London 23, 495-566. doi: 10.1111/j.1096-3642.1860.tb00146.x

Beccaloni, G. W. (1997). Vertical stratification of ithomiine butterfly (Nymphalidae: Ithomiinae) mimicry complexes: the relationship between adult flight height and larval host-plant height. Biol. J. Linn. Soc. 62, 313-341. doi: 10.1111/j.1095-8312.1997.tb01629.x

Briolat, E. S., Burdfield-Steel, E. R., Paul, S. C., Rönk,ä, K. H., Seymoure, B. M., Stankowich, T., et al. (2019). Diversity in warning coloration: selective paradox or the norm? Biol. Rev. 94, 388-414. doi: 10.1111/brv. 12460

Bro-Jørgensen, J. (2010). Dynamics of multiple signalling systems: animal communication in a world in flux. Trends Ecol. Evol. 25, 292-300. doi: 10.1016/J.TREE.2009.11.003

Burns, K. C. (2010). Is crypsis a common defensive strategy in plants? Speculation on signal deception in the New Zealand flora. Plant Signal. Behav. 5, 9-13. doi: $10.4161 /$ psb.5.1.10236

Chazot, N., Willmott, K. R., Santacruz Endara, P. G., Toporov, A., Hill, R. I., Jiggins, C. D., et al. (2014). Mutualistic mimicry and filtering by altitude shape the structure of Andean butterfly communities. Am. Nat. 183, 26-39. doi: $10.1086 / 674100$

Chouteau, M., Arias, M., and Joron, M. (2016). Warning signals are under positive frequency-dependent selection in nature. Proc. Natl. Acad. Sci. U.S.A. 113, 2164-2169. doi: 10.1073/PNAS.1519216113

Cott, H. B. (1940). Adaptive Coloration in Animals. London: Methuen \& Co.

De Bona, S., Valkonen, J. K., López-Sepulcre, A., and Mappes, J. (2015). Predator mimicry, not conspicuousness, explains the efficacy of butterfly eyespots. Proc. Biol. Sci. 282:20150202. doi: 10.1098/rspb.2015.0202

de Jager, M. L., and Anderson, B. (2019). When is resemblance mimicry? Funct. Ecol. 13346, 1365-2435. doi: 10.1111/1365-2435.13346

Font, E. (2018). Mimicry, camouflage and perceptual exploitation: the evolution of deception in nature. Biosemiotics 12, 1-18. doi: 10.1007/s12304-0189339-6
The evolution of mimetic signals involves a wide variety of selective pressures, but also a large variety of traits (Rojas et al., 2018; Briolat et al., 2019). We highlighted here that the same phenotypic trait can be shaped by different selective forces in the different species involved in mimicry. Such distinction could help to disentangle the selective forces shaping the complex evolution of mimicry and may improve our comprehension of this defensive strategy.

\section{AUTHOR CONTRIBUTIONS}

TdS and TA developed the ideas presented in this paper and wrote the manuscript.

\section{ACKNOWLEDGMENTS}

We are grateful to P.-A. Crochet and T. N. Sherratt for comments on earlier versions of the manuscript. We also thank P. Jabłoński, S. Lev-Yadun, and D. Pfennig for suggestions that improved the paper.

Gianoli, E., and Carrasco-Urra, F. (2014). Leaf mimicry in a climbing plant protects against herbivory. Curr. Biol. 24, 984-987. doi: 10.1016/J.CUB.2014. 03.010

Gibson, R. W., and Pickett, J. A. (1983). Wild potato repels aphids by release of aphid alarm pheromone. Nature 302, 608-609. doi: 10.1038/302608a0

Greenfield, M. D. (2006). "Honesty and deception in animal signals," in Essays in Animal Behaviour: Celebrating 50 Years of Animal Behaviour, eds J. R. Lucas and L. W. Simmons (Burlington: Elsevier Academic Press), 279-298.

Hasson, O. (1994). Cheating signals. J. Theor. Biol. 167, 223-238. doi: 10.1006/JTBI.1994.1065

Higham, J. P., and Hebets, E. A. (2013). An introduction to multimodal communication. Behav. Ecol. Sociobiol. 67, 1381-1388. doi: 10.1007/s00265-013-1590-x

Huang, J.-N., Cheng, R.-C., Li, D., and Tso, I.-M. (2011). Salticid predation as one potential driving force of ant mimicry in jumping spiders. Proc. Biol. Sci. 278, 1356-1364. doi: 10.1098/rspb.2010.1896

Huey, R. B., and Pianka, E. R. (1977). Natural selection for juvenile lizards mimicking noxious beetles. Science 195, 201-203.

Jamie, G. A. (2017). Signals, cues and the nature of mimicry. Proc. Biol. Sci. 284:20162080. doi: 10.1098/rspb.2016.2080

Johnstone, R. A. (1996). Multiple displays in animal communication: 'backup signals' and 'multiple messages'. Philos. Trans. R. Soc. B Biol. Sci. 351, 329-338. doi: $10.1098 /$ rstb.1996.0026

Kang, C., Cho, H.-J., Lee, S.-I., and Jablonski, P. G. (2016a). Post-attack aposematic display in prey facilitates predator avoidance learning. Front. Ecol. Evol. 4:35. doi: 10.3389/fevo.2016.00035

Kang, C., Moon, H., Sherratt, T. N., Lee, S.-I., and Jablonski, P. G. (2016b). Multiple lines of anti-predator defence in the spotted lanternfly, Lycorma delicatula (Hemiptera: Fulgoridae). Biol. J. Linn. Soc. 120, 115-124. doi: 10.1111/bij.12847

Kikuchi, D. W., and Pfennig, D. W. (2013). Imperfect mimicry and the limits of natural selection. Q. Rev. Biol. 88, 297-315. doi: 10.1086/673758

Lev-Yadun, S. (2016). Defensive (anti-herbivory) Coloration in Land Plants. Cham: Springer International Publishing. doi: 10.1007/978-3-319-42096-7

Londoño, G. A., García, D. A., and Sánchez Martínez, M. A. (2015). Morphological and behavioral evidence of Batesian mimicry in nestlings of a lowland Amazonian bird. Am. Nat. 185, 135-141. doi: 10.1086/679106

Mallet, J., and Barton, N. H. (1989). Strong natural selection in a warning-color hybrid zone. Evolution 43, 421-431. doi: 10.1111/j.1558-5646.1989.tb04237.x 
Mallet, J., and Gilbert, L. E. (1995). Why are there so many mimicry rings? Correlations between habitat, behaviour and mimicry in Heliconius butterflies. Biol. J. Linn. Soc. 55, 159-180. doi: 10.1111/j.1095-8312.1995.tb01057.x

Mallet, J., and Joron, M. (1999). Evolution of diversity in warning color and mimicry: polymorphisms, shifting balance, and speciation. Annu. Rev. Ecol. Syst. 30, 201-233. doi: 10.1146/annurev.ecolsys.30.1.201

Maynard-Smith, J., and Harper, D. (2003). Animal Signals. Oxford University Press.

McIver, J. D., and Stonedahl, G. (1993). Myrmecomorphy: morphological and behavioral mimicry of ants. Annu. Rev. Entomol. 38, 351-377. doi: 10.1146/annurev.en.38.010193.002031

Merrill, R. M., Wallbank, R. W. R., Bull, V., Salazar, P. C. A., Mallet, J., Stevens, M., et al. (2012). Disruptive ecological selection on a mating cue. Proc. R. Soc. B Biol. Sci. 279, 4907-4913. doi: 10.1098/rspb.2012.1968

Motyka, M., Kampova, L., and Bocak, L. (2018). Phylogeny and evolution of Müllerian mimicry in aposematic Dilophotes: evidence for advergence and size-constraints in evolution of mimetic sexual dimorphism. Sci. Rep. 8:3744. doi: 10.1038/s41598-018-22155-6

Nelson, X. J., and Card, A. (2016). Locomotory mimicry in ant-like spiders. Behav. Ecol. 27, 700-707. doi: 10.1093/beheco/arv218

Penney, H. D., Hassall, C., Skevington, J. H., Abbott, K. R., and Sherratt, T. N. (2012). A comparative analysis of the evolution of imperfect mimicry. Nature 483, 461-464. doi: 10.1038/nature10961

Poulton, E. (1890). The Colours of Animals: Their Meaning and Use, Especially Considered in the Case of Insects. New York, NY: D. Appleton and Co.

Quicke, D. L. J. (2017). Mimicry, Crypsis, Masquerade and Other Adaptive Resemblances. Oxford: Wiley Blackwell.

Rojas, B., Burdfield-Steel, E., De Pasqual, C., Gordon, S., Hernández, L., Mappes, J., et al. (2018). Multimodal aposematic signals and their emerging role in mate attraction. Front. Ecol. Evol. 6:93. doi: 10.3389/fevo.2018.00093

Rudh, A., and Qvarnström, A. (2013). Adaptive colouration in amphibians. Semin. Cell Dev. Biol. 24, 553-561. doi: 10.1016/J.SEMCDB.2013.05.004

Ruxton, G. D., Allen, W. L., Sherratt, T. N., and Speed, M. P. (2018). Avoiding Attack: The Evolutionary Ecology of Crypsis, Aposematism, and Mimicry. Oxford University Press.

Scott-Phillips, T. C. (2008). Defining biological communication. J. Evol. Biol. 21, 387-395. doi: 10.1111/j.1420-9101.2007.01497.x

Silva, I., Crane, M., Artchawakom, T., Suwanwaree, P., and Strine, C. T. (2016). More than meets the eye: change in pupil shape by a mock viper. Front. Ecol. Environ. 14, 453-454. doi: 10.1002/fee.1420
Skelhorn, J., Halpin, C. G., and Rowe, C. (2016). Learning about aposematic prey. Behav. Ecol. 27, 955-964. doi: 10.1093/beheco/ arw009

Smith, S. M. (1977). Coral-snake pattern recognition and stimulus generalisation by naive great kiskadees (Aves: Tyrannidae). Nature 265, 535-536. doi: $10.1038 / 265535 \mathrm{a} 0$

Stevens, M. (2005). The role of eyespots as anti-predator mechanisms, principally demonstrated in the Lepidoptera. Biol. Rev. 80, 573-588. doi: $10.1017 /$ S1464793105006810

Vereecken, N. J., and Schiestl, F. P. (2008). The evolution of imperfect floral mimicry. Proc. Natl. Acad. Sci. U.S.A. 105, 7484-7488. doi: 10.1073/pnas.0800194105

Vitt, L. J. (1992). Mimicry of millipedes and centipedes by elongate terrestrial vertebrates. Res. Explor. 8, 76-95.

Waldbauer, G. P. (1970). Mimicry of Hymenopteran antennae by Syrphidae. Psyche A J. Entomol. 77, 45-49. doi: 10.1155/1970/28967

Wallace, A. R. (1882). Dr. Fritz Müller on some difficult cases of mimicry. Nature 26, 86-87. doi: 10.1038/026086a0

Willmott, K. R., Robinson Willmott, J. C., Elias, M., and Jiggins, C. D. (2017). Maintaining mimicry diversity: optimal warning colour patterns differ among microhabitats in Amazonian clearwing butterflies. Proc. R. Soc. B Biol. Sci. 284:20170744. doi: 10.1098/rspb.2017.0744

Wilson, J. S., Jahner, J. P., Forister, M. L., Sheehan, E. S., Williams, K. A., and Pitts, J. P. (2015). North American velvet ants form one of the world's largest known Müllerian mimicry complexes. Curr. Biol. 25, R704-R706. doi: 10.1016/j.cub.2015.06.053

Yamazaki, K., and Lev-Yadun, S. (2015). Dense white trichome production by plants as possible mimicry of arthropod silk or fungal hyphae that deter herbivory. J. Theor. Biol. 364, 1-6. doi: 10.1016/J.JTBI.2014.08.045

Conflict of Interest Statement: The authors declare that the research was conducted in the absence of any commercial or financial relationships that could be construed as a potential conflict of interest.

Copyright (c) 2019 de Solan and Aubier. This is an open-access article distributed under the terms of the Creative Commons Attribution License (CC BY). The use, distribution or reproduction in other forums is permitted, provided the original author(s) and the copyright owner(s) are credited and that the original publication in this journal is cited, in accordance with accepted academic practice. No use, distribution or reproduction is permitted which does not comply with these terms. 